\title{
Identification and validation of genes involved in gastric tumorigenesis
}

\author{
Thangarajan Rajkumar ${ }^{\text {* }}$, Neelakantan Vijayalakshmi, Gopisetty Gopal, Kesavan Sabitha', Sundersingh Shirley², \\ Uthandaraman M Raja ', Seshadri A Ramakrishnan³
}

\begin{abstract}
Background: Gastric cancer is one of the common cancers seen in south India. Unfortunately more than 90\% are advanced by the time they report to a tertiary centre in the country. There is an urgent need to characterize these cancers and try to identify potential biomarkers and novel therapeutic targets.

Materials and methods: We used 24 gastric cancers, 20 Paired normal (PN) and 5 apparently normal gastric tissues obtained from patients with non-gastric cancers (Apparently normal - AN) for the microarray study followed by validation of the significant genes $(n=63)$ by relative quantitation using Taqman Low Density Array Real Time PCR. We then used a custom made Quantibody protein array to validate the expression of 15 proteins in gastric tissues (4 AN, 9 PN and 9 gastric cancers). The same array format was used to study the plasma levels of these proteins in 58 patients with gastric cancers and 18 from patients with normal/non-malignant gastric conditions.

Results: Seventeen genes (ASPN, CCL15/MIP-1 $\delta$, MMP3, SPON2, PRSS2, CCL3, TMEPAI/PMEPAI, SIX3, MFNG, SOSTDC1, SGNE1, SST, IGHA1, AKR1B10, FCGBP, ATP4B, NCAPH2) were shown to be differentially expressed between the tumours and the paired normal, for the first time. EpCAM ( $p=0.0001)$, IL8 $(p=0.0003), C C L 4 / M I P-1 \beta$ $(p=0.0026), C C L 20 / M I P-3 \alpha(p=0.039)$ and TIMP1 $(p=0.0017)$ tissue protein levels were significantly different (Mann Whitney $U$ test) between tumours versus AN \& PN. In addition, median plasma levels of IL8, CXCL9/MIG, CCL3/MIP-1 $\alpha$, CCL20/MIP-3 $\alpha$, PDGFR-B and TIMP1 proteins were significantly different between the non-malignant group and the gastric cancer group. The post-surgical levels of EpCAM, IGFBP3, IL8, CXCL10/IP10, CXCL9/MIG, CCL3/MIP-1 $\alpha$, CCL20/MIP-3 $\alpha$, SPP1/OPN and PDGFR-B showed a uniform drop in all the samples studied.

Conclusions: Our study has identified several genes differentially expressed in gastric cancers, some for the first time. Some of these have been confirmed at the protein level, as well. Some of these proteins will need to be evaluated further for their potential as diagnostic biomarkers in gastric cancers and some could be useful as follow-up markers in gastric cancer.
\end{abstract}

\section{Introduction}

Gastric cancer is one of the common cancers seen in South India, ranked $2^{\text {nd }}$ among men and $5^{\text {th }}$ among women in the Chennai Metropolitan area [1]. Of the patients presenting to the tertiary Institution, more than $90 \%$ are advanced at presentation and only palliative management is feasible in these patients [2]. In 2005 and 2006, a total of 1239 gastric cancer patients were seen at the Institute, of which 211 patients had been previously treated elsewhere. Among the treatment

\footnotetext{
* Correspondence: drtrajkumar@gmail.com

'Dept. of Molecular Oncology, Cancer Institute (WIA), 38, Sardar Patel Road, Chennai - 600036, India

Full list of author information is available at the end of the article
}

naïve patients ( $\mathrm{n}=1028), 61 \%$ were locally advanced and $39 \%$ were with distant metastasis. In view of the advanced nature of the disease and due to poor performance status, only 91 patients came up for surgery with intent to cure. This highlights the problem of lack of early detection for the gastric cancer in India.

In Japan, which has a high incidence of gastric cancer, photofluorography screening is done as a screening program for the population, resulting in early detection of lesions, some confined to mucosa only [3]. Such a procedure is unlikely to be the solution in a large country such as India. In view of the subtle symptoms such as indigestion, gradual weight loss which are generally ignored, most patients present with advanced disease.
C Biomed Central

C 2010 Rajkumar et al; licensee BioMed Central Ltd. This is an Open Access article distributed under the terms of the Creative Commons Attribution License (http://creativecommons.org/licenses/by/2.0), which permits unrestricted use, distribution, and reproduction in any medium, provided the original work is properly cited. 
It is therefore essential to develop reliable screening tests which can help in early detection of the disease. Serum based tests for Pepsinogen and $\mathrm{H}$. pylori antibody have not gained widespread acceptance and have not been considered for screening individuals by the National Cancer Center, Tokyo, Japan [3]. The diagnostic test should be preferably blood or urine sample based and needs to be specific.

Among the major risk factors for gastric cancer, diet plays an important role. Consumption of salted food (fish and meat) and tobacco are associated with an increased risk [4-6]. Chronic atrophic gastritis and intestinal metaplasia have been considered as pre-malignant changes in the gastric mucosa. Tobacco smoking, H. pylori, diets with high content of salt, nitrites and nitrates, and low intake of fruits and vegetables are known risk factors for chronic atrophic gastritis [7]. The south Indian diet traditionally consists of high chilly content and deep fried food, with the oil used for frying undergoing several cycles of usage before being discarded and hence containing a high content of carcinogens $[5,8,9]$.

Gastric cancers are predominantly adenocarcinomas and could be of three sub-types - Intestinal, Diffuse and Mixed [10]. The Intestinal type of gastric cancer is usually seen in the distal part of stomach, has precancerous stages and comprises of cohesive cancer cells forming gland like structures [11]. Most of the intestinal types are well to moderately differentiated (WHO Classification). The Diffuse type consists of individual cancer cells infiltrating and spreading far beyond its macroscopic borders. They are usually poorly differentiated to undifferentiated [12]. In Chennai, distal tumours are more common than proximal cancers.

Gene expression studies in different cancers have helped in identifying genes involved in the process of tumorigenesis [13]. Microarray studies comparing the gene expression differences between normal stomach and gastric cancer [14], between young and elderly gastric cancer patients' tumours [15], between primary tumour and metastatic lesions [16] have been reported. Our study compares the gene expression between apparently normal gastric tissues obtained from patients with non-gastric cancers (Apparently normal - AN), gastric tissue samples well away from the tumor and confirmed by frozen section not to have tumour cells (Paired normal - PN) and gastric cancers (Tumours - T). This is the first study to look into the gene expression patterns of gastric cancers in south Indian patients and validate some of these genes at the protein level for their potential as biomarkers for gastric cancer.

\section{Materials and methods}

Five AN samples (2 from patients with Hypopharyngeal cancer, 1 from upper oesophageal squamous cell carcinoma, 1 from peri-ampullary carcinoma, 1 from pancreatic cancer) from patients who underwent stomach resection as part of their primary surgery were included in the study. In addition, 24 gastric cancers and $20 \mathrm{PN}$ were included in the study. All the patients provided their informed consent for the study, which was approved by the Institutional Ethical committee.

The operative specimens were immediately processed and sections were taken for frozen section. Tumour samples with more than $70 \%$ cancer cells; PN and AN samples with no evidence of tumour cells and apparently normal morphology were included in the study.

In addition, blood samples were collected from individuals undergoing oesophagogastroduodenoscopy (OGDscopy) for dyspeptic symptoms and to rule out any upper gastrointestinal tract pathology. Of this, 58 were found to be gastric cancers, 6 were found to have benign pathology in the stomach (gastritis, benign ulcer) and 12 had a normal OGDscopy report. In 8 gastric cancer patients who underwent radical surgery, postoperative blood sample was also collected between day 7 and day 15 except two patients in whom the sample was collected at the time of their first follow-up after surgery (days 55 and 64).

\section{RNA extraction}

The RNA was extracted from the tissue samples using the RNeasy RNA extraction kit (Qiagen, Gmbh, Hilden; Cat no: 74106) as per the manufacturer's instructions. The quality of the RNA used for micro-array analysis was checked using the Bioanalyzer and samples with a RNA Integrity Number (RIN) of 7 or more were included in the study. RNA was quantitated using NanoDrop $^{\text {тм }}$ ND1000 (NanoDrop Technologies, USA) spectrophotometer.

\section{Detection of $\mathrm{H}$ pylori}

Analysis for $\mathrm{H}$ pylori in gastric tissue samples was performed using PCR as previously described [17]. PCR primers designed to amplify $\mathrm{S} 2$ region of Vac A gene in the $\mathrm{H}$ pylori genome were used for detection. The reaction amplifies an amplicon of approximately 194 bp length.

\section{Microarray experiment}

$1 \mu \mathrm{g}$ of total RNA from the tumour/PN/AN sample and universal RNA (Stratagene; Cat no: 740000-41) were reverse transcribed using Array script at $42^{\circ} \mathrm{C}$ for $2 \mathrm{hrs}$ to obtain cDNA using the Amino Allyl MessageAmp II aRNA amplification kit (Ambion, Austin, Tx; Cat no: AM1797). The cDNA was amplified, labelled, hybridized and slides scanned as described earlier [18].

All the raw data files have been submitted to GEO with an assigned GEO accession number - GSE17154. 


\section{Microarray data analysis}

The Foreground and Background Median intensity for Cy3 and Cy5, were imported into BRB-ArrayTools software [19] using the Import wizard function. Background correction was not done. Global normalization was used to median centre the log-ratios on each array in order to adjust for differences in labelling intensities of the Cy3 and $\mathrm{Cy} 5$ dyes. The data was analysed using the Class comparison module [20] in the BRB-ArrayTools software.

\section{Class Comparison in BRB-Array Tools}

We identified genes that were differentially expressed among the 3 classes (tumour/PN/AN) using the Class Comparison module. Univariate F-test was used and the genes were considered statistically significant if their $\mathrm{p}$ value was $<0.001$. In addition a two fold difference was required between the different classes.

\section{Quantitative Real time PCR}

Real time validation of the gene expression was done using the TLDA real time PCR (Applied Biosystems, Foster City, CA; Cat no: 4342261). Triplicate cDNA template samples were amplified and analysed on the ABI Prism 7900HT sequence detection system (Applied Biosystems, Foster City, CA) as described earlier [18].

The raw data from the Prism 7900HT sequence detection system was imported into Microsoft Excel software for statistical analysis of the data. Among the endogenous reference genes included on the array (18S ribosomal gene; ACTB), ACTB was chosen after visualizing the global $\mathrm{Ct}$ value distribution, for normalizing the data. In addition, HSPE1 which had been included based on the differential expression seen on Microarray, was found to have minimal variation and hence was included as an additional endogenous control. The TLDA assays were run at LabIndia Instruments Pvt Ltd laboratories at Gurgaon, New Delhi.

The AN samples were used as calibrators and the relative quantitation values were calculated for all the genes and the samples.

\section{Gene Ontology Analysis}

The genes found to be differentially expressed in tumours and paired normals' based on the microarray data were imported into the Fatigo module of Babelomics [21] and analysed for over-representation of the $\mathrm{GO}$ terms in comparison to the rest of the genome, using Fisher's exact test for $2 \times 2$ contingency tables. The $\mathrm{p}$ value was set at $<0.05$.

\section{Preparation of Tissue protein lysates and Collection of Plasma}

Protein lysates for analysis using antibody arrays were prepared from $60-80 \mathrm{mg}$ of frozen gastric tissue samples. The tissue samples were ground in the presence of liquid nitrogen using mortar and pestle. The powdered tissue was re-suspended in tissue lysis buffer (Tris. HCL pH7.5, $150 \mathrm{mM}$ Sodium chloride, 1\% Sodium deoxycholate, 1\%NP40). Prior to use, lysis buffer was supplemented with Complete mini ${ }^{\text {tix }}$ protease inhibitor cocktail (Roche Diagnostics GMBH, Germany). The protein lysates were subjected to sonication using Vibra cell $^{\text {th }}$ (Sonics Inc., USA) sonicator. The lysates were cleared by centrifugation and quantitated using Coomassie Plus-Bradford assay ${ }^{\text {Tum }}$ reagent (Pierce Inc., USA) as per manufacturer's protocol. The quality of the proteins was analysed by resolving $50 \mu \mathrm{g}$ of the lysate on $10 \%$ sodium dodecyl sulfate polyacrylamide (SDS) gel and subsequently visualized by staining using Coomassie Blue.

Plasma was obtained from $5 \mathrm{ml}$ of blood collected in the presence of $200 \mu \mathrm{l}$ of $10 \%$ ethylene diamine tetra acetic acid (EDTA). The plasma isolated from the blood samples was centrifuged at $3000 \mathrm{~g}$ and stored at $-80^{\circ} \mathrm{C}$ in aliquots.

\section{Antibody Arrays}

Custom antibody arrays Quantibody ${ }^{\mathrm{mi}}$ array (Catalogue number: QAA-CUST) based on a multiplex ELISA system for quantitative measurement of multiple proteins purchased from Ray Biotech, Inc, USA was used to study protein expression levels in gastric tissues and plasma samples $[22,23]$. The following genes (CXCL5/ ENA-78, CXCL8/IL8, CXCL10/IP10, CXCL9/MIG, CCL3/MIP-1 $\alpha$, CCL15/MIP-1 $\delta$, EpCAM, MMP3, SPP1/ OPN, TIMP1, Adipsin/CFD, CCL4/MIP-1 $\beta$, CCL20/ MIP-3 $\alpha$, PDGFR-B and IGFBP-3) found to be overexpressed in gastric cancers relative to $\mathrm{PN}$ and $\mathrm{AN}$ (with the exception of CFD/Adipsin which was overexpressed in PN relative to gastric cancers and $\mathrm{AN}$ ) were studied for their protein levels in tumour, corresponding PN and in AN tissues. In addition, plasma levels of these proteins in patients who had undergone OGDscopy were estimated using the same array format (58 gastric cancer patients, 6 with benign gastric or duodenal ulcer or gastritis and 12 with normal OGDscopy report). In 8 gastric cancer patients who had undergone radical surgery, pre and post-operative samples were collected and analyzed.

The assay was performed as described by the manufacturer's protocol. Briefly, in the case of the tissue lysates $100 \mu \mathrm{g}$ of the protein lysate was prepared by diluting the tissue lysate stock solution using sample diluent buffer supplied by the manufacturer to a final concentration of $1 \mathrm{mg} / \mathrm{ml} .100 \mu \mathrm{l}$ of the diluted lysate was incubated in the array chamber for 2 hours. In the case of the plasma samples, the plasma was diluted with sample diluent buffer supplied with the kit at a ratio of 
1:1. $100 \mu \mathrm{l}$ of the diluted plasma sample was incubated in the array chamber for 2 hours. For every array experiment, standards supplied along with the kit were freshly prepared as described by the manufacturers protocol and included along with a sample diluent buffer control (negative control) which neither had standard or samples. The arrays were processed as described by the manufacturer's protocol. The slides were scanned at $5 \mu$ resolution and a PMT of 70 using Pro Scan Array ${ }^{\mathrm{TM}}$ (Perkin Elmer Inc., USA). At these scanner settings the signals from the highest standard concentration did not reach saturation. The data was analyzed using the Quantibody Q-Analyzer, an array specific, Microsoft Excel based program, supplied with the custom arrays.

\section{Statistical analysis}

The median and range for the plasma values were calculated using Microsoft Excel ${ }^{\mathrm{T} M}$ spread sheet software (Microsoft, Inc.). Mann Whitney U test (http://faculty. vassar.edu/lowry/utest.html) was used to study the significance of the median values of the plasma and two tailed test was used for obtaining the $\mathrm{p}$ value.

\section{Results}

The clinico-pathological details of all the patients, whose samples were used for the microarray analysis and their tumour samples, are given in Additional File 1 and 2. The clinico-pathologic details of the patients from whom blood samples were obtained for estimation of the plasma levels of cytokines/chemokines/growth factors is given in Additional File 3.

Of the 24 patients whose tumour samples were used for microarray study, 16 were aged more than 45 years of age and 8 were 45 years or less; 18 were males and 6 were females; 5 were tumours arising in the region of cardia, 2 from body and 17 from antrum. All the twenty-four tumours were adenocarcinomas with one of them being poorly differentiated adenocarcinoma with areas of neuro-endocrine features. Among the adenocarcinomas, Intestinal subtype was the most common ( $\mathrm{n}=$ 16), while diffuse subtype was seen in 5 and mixed in 2 . Grade III tumours predominated $(\mathrm{n}=20)$, with no Grade I tumours in our series. Seventeen of 24 were node positive and 4 had distant metastasis at presentation.

Based on the Class Comparison analysis ( $\mathrm{p}$ value $=$ 0.001 and 2 fold difference), we had 61 genes overexpressed in cancer, 66 in paired normal and 61 with a $\mathrm{p}$ value of $<1 \mathrm{e}-07$ in apparently normal (Additional File 4). We used Taqman Relative Quantitation RT-PCR for validation of some of the genes identified by the microarray analysis. ACTB was chosen as an endogenous control, which was in addition to the $18 \mathrm{~S}$ control present in the TLDA card.
All the 49 samples worked in the TLDA assay but 2 genes, C11orf42 and IGLL1 had not worked. HSPE which had been found to have differential expression in the samples in our microarray analysis did not show any variation in the levels, in the TLDA assay and was included as an additional endogenous control. Normalization was done using ACTB and HSPE as endogenous controls. Of the 63 genes selected, excluding the endogenous controls (ACTB and HSPE) and the two genes which had not worked, we had 59 genes for further analysis.

Three of the genes (REG4, CLDN18, MXRA5) had been included for validation of their potential as prognostic marker for failure. However, in the interval between the time that the microarray analysis was completed and the RQ-RT-PCR analysis was done (approximately 3 months) there were additional patients who relapsed and hence the genes were not considered for further analysis as prognostic markers. However, they were included to assess whether they were differentially expressed between PN and tumours.

The list of genes which were identified to be differentially expressed in gastric cancers are given in Table 1 and Table 2. Table 1 lists the genes identified to be differentially expressed in gastric cancer for the first time and Table 2, lists the genes which have been known to be associated with gastric cancer, and found also in our study. (Additional Files 5 and 6 provide information on these genes and the corresponding references). There are four different patterns of gene expression - Pattern 1 - overexpressed in PN and in Tumours; Pattern 2 overexpressed in PN but downregulated in tumours; Pattern 3 - minimal change in PN but overexpressed in Tumours and Pattern 4 - minimal change in PN but downregulated in Tumours (Figure 1).

We then proceeded to confirm the protein expression for some of the genes in the AN $(n=4)$, PN ( $n=9)$ and tumours $(n=9)$. We used the Quantibody array, which is based on the principle of sandwich ELISA to determine the protein levels of 15 cytokines, chemokines and growth factors [22,23]. The Median values and the Range of the levels are given in Table 3. CFD/Adipsin median levels were found to be lower in tumours compared to the levels in $\mathrm{PN}$ and $\mathrm{AN}$ ( $\mathrm{p}=0.0324$ ), while CXCL5/ENA78, CCL20/MIP-3 $\alpha$, IGFBP3, SPP1/OPN and TIMP1 were increased in PN and tumours relative to $\mathrm{AN}$, with higher levels seen in tumours. In contrast, EpCAM, IL8, CXCL10/IP10, CCL3/MIP-1 $\alpha$, CCL4/MIP$1 \beta$, CCL15/MIP-1 $\delta$, PDGFR-B were predominantly elevated in tumours compared to $\mathrm{AN}$ and PN. EpCAM $(\mathrm{p}=0.0001)$, IL8 $(\mathrm{p}=0.0003), \operatorname{MIP}-1 \beta(\mathrm{p}=0.0026)$, MIP-3 $\alpha(\mathrm{p}=0.039)$ and TIMP1 $(\mathrm{p}=0.0017)$ levels were significantly different (Mann Whitney $U$ test) between tumours versus AN \& PN. Additionally, EpCAM 


\begin{tabular}{|c|c|c|c|}
\hline SNO & GENE SYMBOL & UPREGULATION REPORTED IN & REFERENCE \\
\hline 1 & CCL15/MIP5/MIP-1d/LKN1 & NSCLC & [SF5-R1] \\
\hline 2 & ASPN & breast cancer & [SF5-R2] \\
\hline 3 & MMP3 & colorectal cancer & [SF5-R3] \\
\hline 4 & SPON2 & Lung, ovarian, prostate cancers & $\begin{array}{l}\text { [SF5-R4] } \\
\text { [SF5-R5] } \\
\text { [SF5-R6] }\end{array}$ \\
\hline 5 & PRSS22 & ovarian cancer & [SF5-R7] \\
\hline 6 & CCL3/MIP 1A & oral SCC & [SF5-R8] \\
\hline 7 & TMEPAI/PMEPAI & Neuro-endocrine tumours & [SF5-R9] \\
\hline 8 & SIX3 & & \\
\hline 9 & MFNG & Downregulated in cervical cancer & [SF5-R10] \\
\hline 10 & SGNE1/SCG5 & endocrine tumors & \\
\hline 11 & SOSTDC1 & Downregulated in renal cancer & [SF5-R11] \\
\hline 12 & SST & Downregulated in oesophageal adenocarcinoma & [SF5-R12] \\
\hline 13 & $\mid \mathrm{GHA}$ & & \\
\hline 14 & AKR1B10 & Increased in Barrett's epithelium & [SF5-R13] \\
\hline 15 & FCGBP & Down regulated in colon ca & [SF5-R14] \\
\hline 16 & ATP4B & & \\
\hline 17 & NCAPH2 & & \\
\hline
\end{tabular}

$(\mathrm{p}=0.0004)$, IL8 $(\mathrm{p}=0.0015)$ and MIP-1 $\beta(\mathrm{p}=0.0061)$ were significantly elevated in tumours compared to their corresponding PN.

The plasma levels of the 15 cytokines/chemokines/ growth factors were estimated using the Quantibody array. The 18 non-malignant cases (12 with no abnormality detected by OGDscopy and 6 with benign pathology in the stomach) were clubbed together and the median values were compared between the tumours and the non-malignant group. Mann Whitney U test was performed to assess the statistical significance (two tailed test). IL8, CXCL9/MIG, CCL3/MIP-1 $\alpha$, CCL20/ MIP-3 $\alpha$, PDGFR-B and TIMP1 plasma levels were significantly different between the non-malignant group and the gastric cancer group (Table 4). SPP1/OPN level were also higher in gastric cancer patients compared to the non-malignant group but was borderline significant $(\mathrm{p}=0.05)$. The post-surgical levels of EpCAM, IGFBP3, IL8, CXCL10/IP10, CXCL9/MIG, CCL3/MIP-1 $\alpha$, CCL20/MIP-3 $\alpha$, SPP1/OPN and PDGFR-B showed a uniform drop in all the 8 samples studied. In contrast TIMP1, CCL15/MIP-1 $\delta$ and CFD/Adipsin levels actually increased in the post-operative period in most of the samples (Figure 2).

The plasma levels of the cytokines/chemokines/growth factors were then correlated with the clinico-pathologic features. 28 of the 58 gastric cancer patients had undergone a potentially curative radical surgery (R0 resection) and 6 patients underwent R1 resection only. These 34 pathologic specimens were available for pathologic correlations ( $\mathrm{pT}, \mathrm{pN}, \mathrm{pStage}$, perinodal spread, lymphatic emboli, vascular emboli), while survival analysis was done on 28 patients who had undergone a R0 resection. Ten patients underwent palliative surgical procedures while 13 patients declined surgery or were unfit for any intervention other than supportive care. One patient had an undifferentiated cancer, which on additional Immunohistochemical studies was found to be a primary gastric lymphoma, diffuse large B cell type. Plasma levels for MMP3 where higher in males compared to females (Median value $16772.1 \mathrm{pg} / \mathrm{ml}$ versus $8512.5 \mathrm{pg}$ / $\mathrm{ml})$ ( $\mathrm{p}$ value $=0.011)$; patients with tumours in the cardia were found to have higher plasma levels of MIG compared to other sites [antrum, pylorus and body] (Median value of $18203.9 \mathrm{pg} / \mathrm{ml}$ versus $7204.1 \mathrm{pg} / \mathrm{ml}$ ) ( $\mathrm{p}$ value $=0.032)$; TIMP1 levels were higher in tumours arising from the antrum and pylorus compared to those arising from the body and cardia of the stomach (Median value $125639.5 \mathrm{pg} / \mathrm{ml}$ versus $90820 \mathrm{pg} / \mathrm{ml}$ ) ( $\mathrm{p}$ value =0.026); IP10, MMP3 and MIP-3 $\alpha$ plasma levels were higher in patients with tumours which had lymphatic emboli compared to those which were negative (Median values of $1691.4,17761.2,2103.8$ versus $543.8,8359.2$, $250.7 \mathrm{pg} / \mathrm{ml}$, respectively) (p value $0.009,0.009,0.018$, respectively). Plasma level of MMP3 was also associated with vascular emboli but this did not achieve statistical significance. The plasma levels of the cytokines were not significantly associated with disease-free or overall survival in the 28 patients who underwent radical curative surgery. 
Table 2 Genes known to be involved in gastric cancer tumorigenesis identified in this study [References and details in Additional File 5]

\begin{tabular}{|c|c|c|c|}
\hline S NO & GENE SYMBOL & UP OR DOWN REGULATED & REFERENCE \\
\hline 1 & CTSB & Up-regulated especially in cardia tumours & [SF6-R1] \\
\hline 2 & SPARC/Osteonectin & Up-regulated & [SF6-R2] \\
\hline 3 & COL1A1 & Up-regulated & [SF5-R3] \\
\hline 4 & COL1A2 & Up-regulated & [SF5-R3] \\
\hline 5 & COL4A1/Arresten & Up-regulated & [SF5-R4] \\
\hline 6 & CXCL1/GRO1/MGSA & Up-regulated & [SF5-R5] \\
\hline 7 & SPP1/osteopontin & Up-regulated & [SF5-R6] \\
\hline 8 & CXCL9/MIG & Up-regulated & [SF5-R7] \\
\hline 9 & IL8/CXCL8 & Up-regulated & [SF5-R8] \\
\hline 10 & TIMP1 & Up-regulated & [SF5-R9] \\
\hline 11 & LUM/SLRR2D/LDC & Up-regulated & [SF5-R10] \\
\hline 12 & CXCL5/ENA78 & Up-regulated & [SF5-R11] \\
\hline 13 & CXCL10/INP10/IP10 & Up-regulated & [SF5-R4] \\
\hline 14 & CEACAM6 & Up-regulated & [SF5-R12] \\
\hline 15 & REGIV & Up-regulated & [SF5-R13] \\
\hline 16 & S100A10/ANX2L/CAL1L & Up-regulated & [SF5-R14] \\
\hline 17 & SERPINH1/HSP47/CBP1 & Up-regulated & [SF5-R15] \\
\hline 18 & $\mathrm{CDH} 3$ & Up-regulated & [SF5-R16 \\
\hline 19 & TACSTD1/EPCAM/CD326 & Up-regulated & [SF5-R17] \\
\hline 20 & IFITM1/LEU13 & Up-regulated & [SF5-R18] \\
\hline 21 & CTHRC1 & Up-regulated & [SF5-R19] \\
\hline 22 & SULF1 & Up-regulated & [SF5-R20] \\
\hline 23 & RNASE1 & Down-regulated & [SF5-R21] \\
\hline 24 & PGC & Down-regulated & [SF5-R22] \\
\hline 25 & PGA5 & Down-regulated & [SF5-R22] \\
\hline 26 & GIF & Down-regulated & [SF5-R23] \\
\hline 27 & LTF & Down-regulated & [SF5-R24] \\
\hline 28 & TFF1 & Down-regulated & [SF5-R25] \\
\hline 29 & CLDN18 & Down-regulated & [SF5-R26] \\
\hline 30 & CFD/Adipsin & Secreted by gastric ca cell lines & [SF5-R27] \\
\hline 31 & GHRL/Obestatin & Down-regulated & [SF5-R28] \\
\hline 32 & LIPF & Down-regulated & [SF5-R29] \\
\hline 33 & ANXA10 & Down-regulated & [SF5-R30] \\
\hline
\end{tabular}

\section{Discussion}

This is the first gene expression study on gastric cancer from south India, which has a high incidence rate for gastric cancers in India. As discussed earlier, diet related factors play an important role in the pathogenesis of these cancers $[4-6,8,9]$.

In this study we have compared the gene expression profile of apparently normal (gastric tissue obtained from patients undergoing gastric resection for Non-gastric cancers), paired normal (gastric tissue well away from the gastric tumour and confirmed not to have any tumour cells) and the gastric tumours. Most studies have used the paired normal and the tumour for studying the gene expression patterns $[14,24,25]$ while others have compared biopsies from erosive gastritis, atrophic gastritis, intestinal metaplasia and gastric cancers [26].
A few studies have used Laser capture micro-dissection to profile the gastric cancer cells [27].

Our study has identified for the first time several genes $(n=17)$ as being differentially expressed in gastric cancers (Table 1). In addition, 33 genes known to have been involved in gastric cancer were confirmed in our study as well (Table 2). Additional Files (5 and 6) indicate the known function of the genes obtained from Gene Cards [28].

Our study identified a large number of genes associated with the extracellular matrix (SPARC, SERPINH1/HSP47, COL1A1, COL1A2, COL4A1, MMP3, TIMP1, PRSS2, CDH3, SPP1, IL8, CTSB, LUM, CEACAM, CTHRC1, SULF1, ASPN, SPON2 and CLDN18) and chemokine activity, to be differentially expressed in gastric cancers. 


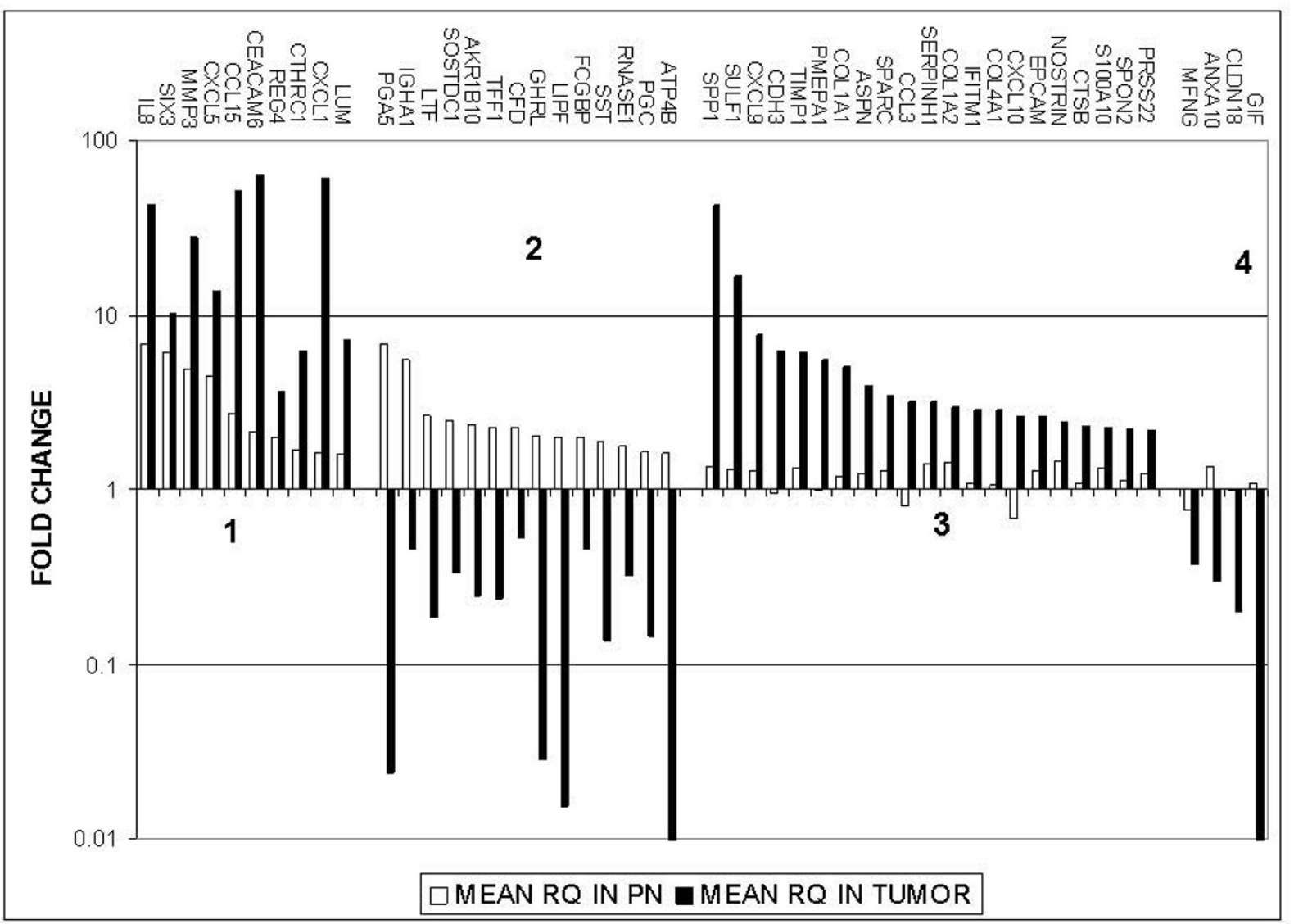

Figure 1 RQ values of Paired normals $(P N)(n=20)$ and Tumour $(n=24)$, using apparently normal $(A N)(n=5)$ as calibrator. The fold change is relative to the apparently normals.

SPARC, SERPINH1 and CTHRC1 are involved in collagen synthesis; while MMP3, CTSB are involved in breakdown of extracellular matrix, and TIMP could inhibit MMP activity. PRSS2 converts inactive MMP3 into active MMP3 while SPARC can activate MMP2. TIMP has additional tumour promoting role in oncogenesis, stimulating proliferation [29] and inhibiting apoptosis $[30,31]$ thereby contributing to the malignant phenotype. ASPN, an extracellular matrix protein, which inhibits TGF- $\beta$ and BMP2, is overexpressed in the gastric cancers relative to the paired normal [32].

REG4 has been reported to be a marker for peritoneal metastasis in gastric cancer [33] and this was supported by our study which showed that REG4 overexpression is associated with metastatic disease. SERPINH1 (HSP47) was also associated with metastatic disease and had been shown earlier to be a marker for metastatic tumour cells [34].

Some of the tumour suppressor genes identified in our study included Lactotransferrin (LTF), MFNG and
SOSTDC1. LTF has been found to inhibit invasiveness of the gastrointestinal tumour cell lines [35]. MFNG has been shown to inhibit Jagged-Notch signalling in cervical cancer cells. Introduction of MFNG into the CaSki cervical cancer cell line leads to inhibition of its tumorigenicity [36].

Several cytokine mRNAs' (CCL3/MIP-1 $\alpha$, CCL15/

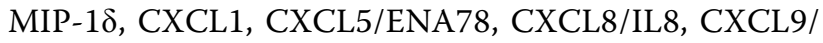
MIG, CXCL10/IP10) were found to be overexpressed in the tumours while CCL15/MIP-1 $\delta$, CXCL5/ENA78 and IL8 mRNAs' were overexpressed in paired normals, as well. However, at the protein level, there was up-regulation of CXCL5/ENA78, CCL20/MIP3- $\alpha$, IGFBP3, OPN and TIMP1 in tumours and their PN, indicating that these could be early events in the gastric tumorigenesis. Park et al., (2007) [37] had reported CXCL5/ENA78 overexpression to be associated with late stage gastric cancer and nodal metastasis, using immunohistochemistry (IHC). Our study, using a more sensitive assay, suggests CXCL5/ENA78 to be involved in early phases of 
Table 3 Median values for cytokines and chemokines in an, pn and tumour lysates

\begin{tabular}{|c|c|c|c|c|c|c|}
\hline & $\begin{array}{r}\text { AN } \\
\text { Median in } \mathrm{pg} / \mathrm{ml}\end{array}$ & $\begin{array}{l}\text { AN } \\
\text { Range in } \mathrm{pg} / \mathrm{ml}\end{array}$ & $\begin{array}{r}\text { PN } \\
\text { Median in } \mathrm{pg} / \mathrm{ml}\end{array}$ & $\begin{array}{l}\text { PN } \\
\text { Range in } \mathrm{pg} / \mathrm{ml}\end{array}$ & $\begin{array}{r}\text { TUMOUR } \\
\text { Median in } \mathrm{pg} / \mathrm{ml}\end{array}$ & $\begin{array}{l}\text { TUMOUR } \\
\text { Range in } \mathrm{pg} / \mathrm{ml}\end{array}$ \\
\hline CFD/Adipsin & 27295.0 & $22097.9-31759.9$ & 27162.9 & $19515.1-38224.3$ & $13021.0^{*}$ & $9441.5-36873.1$ \\
\hline CXCL5/ENA-78 & 283.8 & $39.3-4206.1$ & 2922.7 & $84.9-31628.7$ & 3978.0 & $723.9-40669.6$ \\
\hline EрСАM & 1466.0 & $905.7-2266.6$ & 2243.5 & $915-8885.8$ & 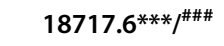 & 8966.1 - 34529 \\
\hline IGFBP-3 & 3149.8 & $124.0-17530.2$ & 12286.0 & $134.6-34036.3$ & 17662.7 & $196.9-55671.5$ \\
\hline IL-8/CXCL8 & 22.1 & $0-62.3$ & 53.1 & $27.4-190.6$ & $1240.4 * * * p^{\# \# \#}$ & $93.1-3660.7$ \\
\hline CXCL10/IP-10 & 20.4 & $1.4-146.1$ & 147.0 & $0.8-3940.9$ & 384.4 & $0.7-1643.1$ \\
\hline CXCL9/MIG & 369.5 & $0-8569.7$ & 4336.1 & $1077.2-19396.6$ & 7540.3 & $727.7-73975.9$ \\
\hline CCL3/MIP-1 $\alpha$ & 0.0 & $0-187.4$ & 203.6 & $0-1177.2$ & 359.0 & $0-3231.5$ \\
\hline CCL4/MIP-1 $\beta$ & 49.5 & $0-261.8$ & 94.3 & $0-335.8$ & $578.6 * * \rho^{\#}$ & $28.7-1185.2$ \\
\hline 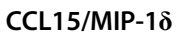 & 86.0 & $54-157.3$ & 169.3 & $51.7-748.9$ & 374.3 & $63.4-2825.4$ \\
\hline CCL20/MIP-3 $\alpha$ & 859.3 & $76.1-1784.8$ & 3049.6 & $893-16262.9$ & $4773.4^{*}$ & $1014.4-13280.7$ \\
\hline MMP-3 & 269.0 & $0-648.6$ & 143.9 & $0-353.1$ & 0.0 & $0-2908.2$ \\
\hline SPP1/OPN & 447.0 & $9.1-896.3$ & 2054.0 & $193.6-3183.7$ & 1407.1 & $12.6-5819.2$ \\
\hline PDGF R-B & 222.3 & $174.3-521.4$ & 295.3 & $184.9-1079.3$ & 578.6 & $123.7-1516.8$ \\
\hline TIMP-1 & 9676.2 & $4373.3-17133.2$ & 27022.2 & $17028.3-194387.8$ & $139365.6^{* *}$ & $48146.4-367203.2$ \\
\hline
\end{tabular}

AN - Apparently normal; PN - Paired normal

$\mathrm{p}$ value significant for $\mathrm{AN}+\mathrm{PN}$ versus Tumour -

* - <0.05; ** $-<0.005$; *** $-<0.0005$ by Mann Whitney U test.

$\mathrm{p}$ value significant for $\mathrm{PN}$ versus Tumour -

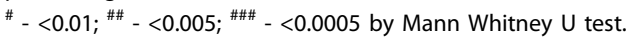

tumourigenesis as well. Interestingly, CXCL5/ENA78 was found to induce a proliferative response in nontransformed prostate cell lines [38]. CCL20/MIP-3 $\alpha$ has been known to be expressed in inflamed gastric tissue and plays a role in H.pylori induced gastritis [39]. Using IHC, IGFBP3 was found to be overexpressed in gastric cancers relative to the normal gastric tissue [40]. SPP1/ OPN has also been reported to be overexpressed in gastric cancers and increasing levels have been detected with progression of disease [41]. TIMP1 is an inhibitor of matrix metalloproteinases but at the same time can also induce cell proliferation and has an anti-apoptotic effect. It has been reported to be overexpressed in gastric cancer cells and in the inflammatory cells of the stromal element of the tumour [42].

EpCAM, IL8, CXCL10/IP10, CCL3/MIP-1 $\alpha$, CCL4/ MIP-1 $\beta$, CCL15/MIP-1 $\delta$, PDGFR-B protein were found to be expressed predominantly in tumours only,

Table 4 Median values for cytokines and chemokines in plasma from non-malignant patients versus plasma from patients with gastric carcinomas

\begin{tabular}{|c|c|c|c|c|}
\hline & $\begin{array}{l}\text { MEDIAN for non-malignant } \\
(\mathrm{n}=18) \text { (in } \mathrm{pg} / \mathrm{ml} \text { ) }\end{array}$ & RANGE (in pg/ml) & $\begin{array}{l}\text { MEDIAN for tumours } \\
(\mathrm{n}=58) \text { (in } \mathrm{pg} / \mathrm{ml})\end{array}$ & RANGE (in pg/ml) \\
\hline CFD/Adipsin & 71520.0 & $58000.8-77527.9$ & 69236.4 & $27926.9-95255.7$ \\
\hline CXCL5/ENA-78 & 1100.6 & $0-7203.2$ & 1702.8 & $0-11588.5$ \\
\hline EpCAM & 1789.8 & $0-13627.3$ & 3527.1 & $0-35009.2$ \\
\hline IGFBP-3 & 119467.1 & $20164.6-174498$ & 110395.1 & $0-979359.6$ \\
\hline IL-8/CXCL8 & 22.5 & $0-69.9$ & $48.9^{*}$ & $0-396.3$ \\
\hline CXCL10/IP-10 & 670.2 & $0-3328.9$ & 931.1 & $0-5158.9$ \\
\hline CXCL9/MIG & 6069.2 & $0-18739.7$ & 7561.8* & $505-6-86999$ \\
\hline CCL3/MIP-1 $\alpha$ & 1464.8 & $0-10602.2$ & $2335.1^{*}$ & $0-32199$ \\
\hline CCL4/MIP-1 $\beta$ & 43.0 & $0-440.1$ & 127.9 & $0-2138.5$ \\
\hline 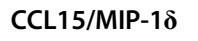 & 6628.8 & $1237.8-13178.1$ & 5577.9 & $696.3-11054.4$ \\
\hline CCL20/MIP-3 $\alpha$ & 139.9 & $0-1994.1$ & $654.6 \#$ & $0-12013.1$ \\
\hline MMP-3 & 10966.2 & $3891.2-38928.9$ & 13680.1 & $1358.7-80588.8$ \\
\hline SPP1/OPN & 4621.5 & $0-20518.1$ & 8680.5 & $0-110373.2$ \\
\hline PDGF R-B & 1391.5 & $0-5461.8$ & $2300.5^{*}$ & $0-34754.4$ \\
\hline TIMP-1 & 31048.9 & $15603.8-220729.6$ & 98054.6\# & $6252.5-463941$ \\
\hline
\end{tabular}

\# - $\mathrm{p}$ value $<0.01{ }^{*}$ - $\mathrm{p}$ value $<0.05$ by Mann Whitney $U$ test. 


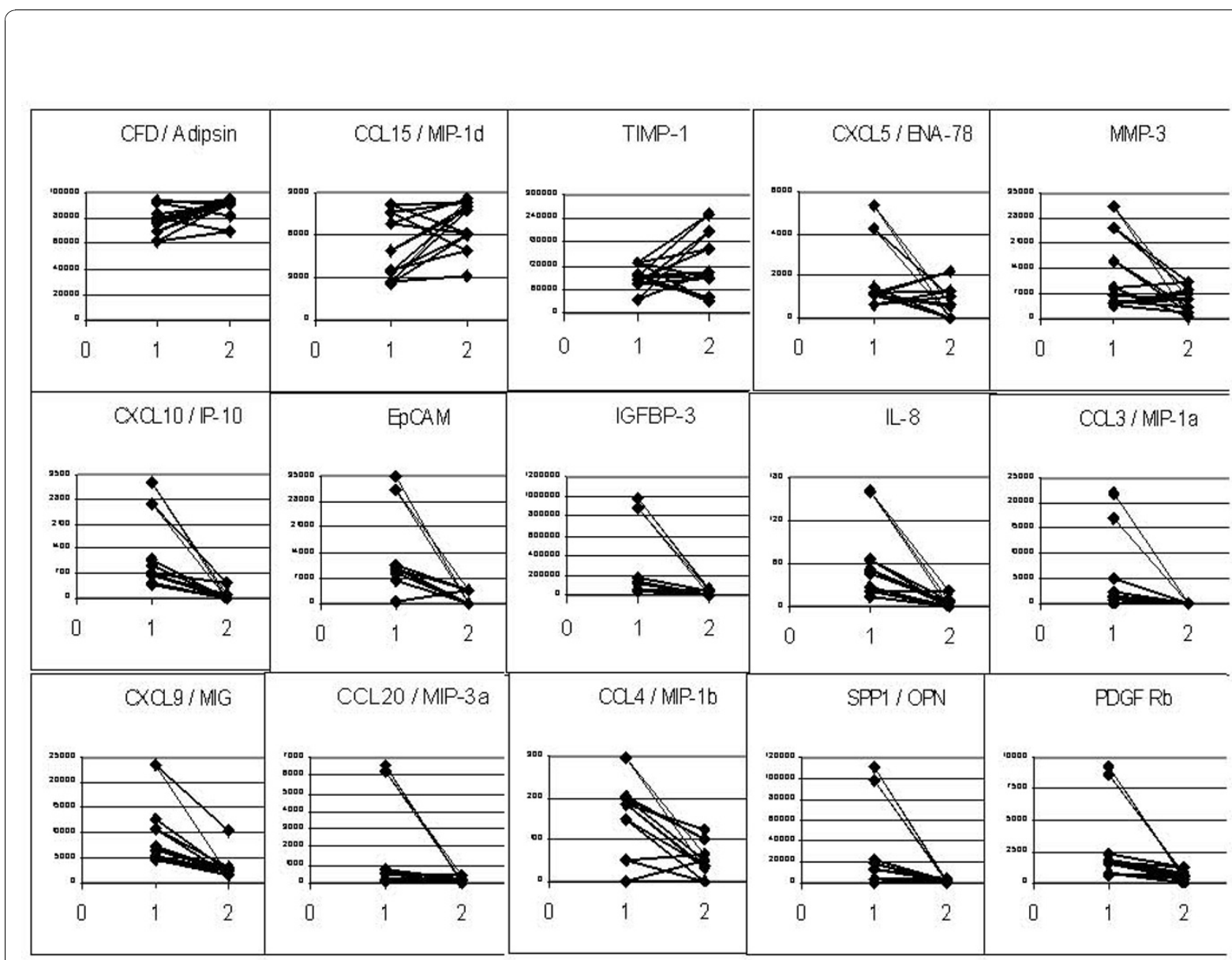

Figure 2 Pre (1) and Post-operative (2) plasma levels of the cytokines/chemokines/growth factors in gastric cancers $(\mathbf{n}=\mathbf{8})$. The plasma levels were measured using the Quantibody array, which uses the principle of sandwich ELISA in a multiplex format. The details for the estimation of the levels are provided in the Methods section.

suggesting that they could be involved in the later stages of gastric tumorigenesis. EpCAM is expressed by most epithelial cell membranes and in gastrointestinal carcinomas. It has been shown to be overexpressed in gastric carcinomas and when downregulated by siRNA, it leads to decrease in cell proliferation, cell cycle arrest and suppressed tumour formation in nude mice [43]. IL8 is a potent pro-angiogenic and inflammatory chemokine [44] and has been found to play a role in the inflammatory response to H.pylori [45]. It has also been shown to be involved in the invasiveness and angiogenesis of several cancers including pancreatic cancer [46]. Of the three related Macrophage inflammatory proteins (CCL3/ MIP - $1 \alpha$, CCL4/MIP-1 $\beta$ and CCL15/MIP-1 $\delta$ ), CCL4/ MIP-1 $\beta$ was the most differentially expressed. This betachemokine has been reported to be highly expressed in diffuse type gastric cancers [47]. Inspite of the production of these MIP proteins, the immune response to the tumours is not effective probably due to functional defects in the effector cells [48]. Chung et al (1992) [49] reported the presence of PDGFR-B mRNA and protein in the gastric tumours (using in situ hybridization and IHC) but not in the adjacent non-malignant mucosa, which is similar to our data.

We had chosen a large number of potentially secreted proteins for our validation of the microarray data using Taqman Real Time PCR (TLDA assay). Subsequently we evaluated 15 proteins which are secreted, for validation using the Quantibody protein array, both in gastric tissues and in the plasma. The Median values and the range of the 15 proteins in the plasma are given in Table 4. CCL20/MIP-3 $\alpha$, TIMP1, IL8, PDGFR-B, CCL3/ MIP- $1 \alpha$ and CXCL9/MIG were significantly elevated in the plasma from the gastric cancer patients compared to the plasma from individuals with no visible upper gastro-intestinal pathology or those with benign lesions in stomach. As in our study, TIMP1 levels have been found to be elevated in gastric cancer patients compared 
to healthy controls $[50,51]$. CXCL5 levels were found to be higher in late stage gastric cancer patients compared to levels in patients with benign conditions [37].

The pre- and post-operative paired plasma samples from gastric cancer patients who underwent radical surgery showed concordant drop for most of the proteins studied, except TIMP1, MIP- $1 \delta$ and Adipsin. TIMP1 levels are known to be elevated following tissue injury. TIMP1 levels have been found to be elevated in the immediate post-operative period after curative resection for colo-rectal cancers and it took between 28 - 60 days to fall below the pre-operative levels [52]. Parsons et al., (2004) [53] have shown TIMP1 to be involved in decreased degradation of extracellular matrix (ECM) by blocking matrix metalloproteinase activity and enhanced survival of hepatic stellate cells which are a major source of ECM, leading to fibrosis in liver following chemical injury. CCL15/MIP- $1 \delta$ has been shown to be expressed constitutively in the intestinal epithelial cells and play a role in chronic inflammatory pathologies of the intestine such as Crohn's disease and ulcerative colitis [54]. It is not clear whether its level could be elevated following surgery. This should be borne in mind if these markers are planned to be evaluated as biomarkers for either diagnosis or prognosis or follow-up.

In conclusion, our study has identified several genes differentially expressed in gastric cancers, some for the first time. Some of these have been confirmed at the protein level, as well. In addition, we have shown some of the proteins (CCL20/MIP-3 $\alpha$, TIMP1, IL8, PDGFR-B, CCL3/MIP-1 $\alpha$ and CXCL9/MIG) to be detected at a higher level in the plasma from gastric cancer patients than in patients with non-malignant gastric conditions or with normal gastric mucosa. These will need to be evaluated further for their potential as diagnostic biomarkers in gastric cancers. A larger number of patients and a longer duration of follow-up will be required to obtain meaningful prognostic information particularly with regard to survival.

\section{Additional material}

Additional file 1: Clinico-pathologic data of all the patients whose samples were used for microarray analysis. The clinico-pathological details of all the patients (AN, PN and Cancers), whose samples were used for the microarray analysis are given.

Additional file 2: Clinico-pathologic data of only the AN and PN samples. The clinico-pathological details of only the AN and PN samples that were used for the microarray analysis are given.

Additional file 3: Clinico-pathologic details of the patients in whom the plasma levels of the cytokine/chemokine/growth factors were estimated. The clinico-pathologic details of the patients from whom blood samples were obtained for estimation of the plasma levels of cytokines/chemokines/growth factors.
Additional file 4: Results of the Class Comparison analysis of the microarray data. The file provides the results of the Class Comparison analysis done on the microarray data.

Additional file 5: Information on genes reported to be differentially expressed for the first time in gastric cancer References and details of genes reported to be differentially expressed for the first time in gastric cancer.

Additional file 6: Information on genes known to be involved in gastric cancer tumorigenesis identified in this studyReferences and details of genes known to be involved in gastric cancer tumorigenesis identified in this study.

\section{Acknowledgements}

This study was supported by a grant from the Department of Science and Technology, Govt. of India. We would like to acknowledge the help of Dr. R. Swaminathan and Mrs. R. Rama, Dept. of Epidemiology and Tumour registry for her kind help and suggestions with the statistical analysis. We would like to thank Ms. B. Meenakumari for her kind help in collecting the clinical data. We would also like to thank Dr. Alpana Razdan and Dr. Mainak Majumder of LabIndia Instruments Pvt Ltd laboratory, New Delhi for help with the TLDA assay.

\section{Author details}

'Dept. of Molecular Oncology, Cancer Institute (WIA), 38, Sardar Patel Road, Chennai - 600036, India. ${ }^{2}$ Dept. of Pathology, Cancer Institute (WIA), 38, Sardar Patel Road, Chennai - 600036, India. ${ }^{3}$ Dept. of Surgical Oncology, Cancer Institute (WIA), 38, Sardar Patel Road, Chennai - 600036, India.

\section{Authors' contributions}

TR conceived the study; acquired, analysed \& interpreted the data and drafted the article. NV standardized and together with UMR performed the microarray experiments. GG standardized and together with UMR carried out the Quantibody array experiments. KS was involved in the acquisition and analysis of the microarray data. SS carried out all the pathological studies and assessment of samples for the microarray studies. SAR was involved in the clinical management and follow-up of the patients. All the authors read and approved the final version of the manuscript.

\section{Competing interests}

The authors declare that they have no competing interests.

Received: 15 July 2010 Accepted: 24 November 2010

Published: 24 November 2010

\section{References}

1. Shanta V, Swaminathan R, Balasubramaniam S: Cancer incidence and mortality in Chennai, India: 2003-2005. National Cancer Registry Program Cancer Institute (WIA), Chennai; 2008.

2. Shanta V, Swaminathan R, Rama R: Hospital cancer registry. Biennial Report: 2005-06 National Cancer Control Program, Cancer Institute (WIA), Chennai; 2008.

3. Hamashima C, Shibuya D, Yamazaki H, Inoue K, Fukao A, Saito H, Sobue T: The Japanese guidelines for gastric cancer screening. Jpn J Clin Oncol 2008, 38:259-67.

4. Gajalakshmi CK, Shanta V: Lifestyle and risk of stomach cancer: a hospitalbased case-control study. Int J Epidemiol 1996, 25:1146-53.

5. Mathew A, Gangadharan P, Varghese C, Nair MK: Diet and stomach cancer: a case-control study in South India. Eur J Cancer Prev 2000, 9:89-97.

6. Rao DN, Ganesh B, Dinshaw KA, Mohandas KM: A case-control study of stomach cancer in Mumbai, India. Int J Cancer 2002, 99:727-31.

7. Dobrilla G, Benvenuti S, Amplatz S, Zancanella L: Chronic gastritis, intestinal metaplasia, dysplasia and Helicobacter pylori in gastric cancer: putting the pieces together. Ital J Gastroenterol 1994, 26:449-58.

8. Sivaswamy SN, Balachandran B, Sivaramakrishnan VM: Presence of polycyclic aromatic hydrocarbons in some South Indian food components. Indian J Exp Biol 1991, 29:611-4. 
9. Taj S, Nagarajan B: Induction of genotoxicity by salted deep-fried fish and mutton. Mutat Res 1994, 322:45-54

10. Lauren P: The two histological main types of gastric carcinoma: diffuse and so-called intestinal-type carcinoma. An attempt at a histo-clinical classification. Acta Pathol Microbiol Scand 1965, 64:31-49.

11. Fuchs CS, Mayer RJ: Gastric carcinoma. N Engl J Med 1995, 333:32-41.

12. Roukos DH: Relevant prognostic factors in gastric cancer. Ann Surg 2000, 232:719-20.

13. Marinkovic D, Marinkovic T, Kokai E, Barth T, Möller P, Wirth T: Identification of novel Myc target genes with a potential role in lymphomagenesis. Nucleic Acids Res 2004, 32:5368-78.

14. Hippo Y, Taniguchi H, Tsutsumi S, Machida N, Chong JM, Fukayama M, Kodama T, Aburatani H: Global gene expression analysis of gastric cancer by oligonucleotide microarrays. Cancer Res 2002, 62:233-40.

15. Buffart TE, Carvalho B, Hopmans E, Brehm V, Kranenbarg EK, SchaaijVisser TB, Eijk PP, van Grieken NC, Ylstra B, van de Velde CJ, Meijer GA: Gastric cancers in young and elderly patients show different genomic profiles. J Pathol 2007, 211:45-51.

16. Wang L, Zhu JS, Song MQ, Chen GQ, Chen JL: Comparison of gene expression profiles between primary tumor and metastatic lesions in gastric cancer patients using laser microdissection and CDNA microarray. World I Gastroenterol 2006, 12:6949-54.

17. Koehler Cl, Mues MB, Dienes HP, Kriegsmann J, Schirmacher P, Odenthal M: Helicobacter pylori genotyping in gastric adenocarcinoma and MALT lymphoma by multiplex PCR analyses of paraffin wax embedded tissues. Molecular Pathology 2003, 56:36-42.

18. Rajkumar T, Vijayalakshmi N, Sabitha K, Shirley S, Selvaluxmy G, Bose MV Nambaru L: A 7 gene expression score predicts for radiation response in cancer cervix. BMC Cancer 2009, 9:365.

19. BRB-Array Tools version 3.7.0 Patch_1 developed by Dr. Richard Simon and Amy Peng Lam. [http://linus.nci.nih.gov/BRB-ArrayTools.html].

20. Wright GW, Simon R: A random variance model for detection of differential gene expression in small microarray experiments. Bioinformatics 2003, 19:2448-55.

21. Al-Shahrour F, Minguez P, Vaquerizas JM, Conde L, Dopazo J: Babelomics: a suite of web-tools for functional annotation and analysis of group of genes in high-throughput experiments. Nucleic Acids Research 2005, 33: W460-W464.

22. Zhai Y, Zhong Z, Chen CYA, Xia Z, Song L, Blackburn MR, Shyu AB: Coordinated changes in Mrna turnover, translation and RNA processing bodies in bronchial epithelial cells following inflammatory stimulation. Mol Cell Biol 2008, 28:7414-26.

23. Stechova K, Spalova I, Durilova M, Bartaskova D, Cerny M, Cerna M, Pithova P, Chudoba D, Stavikova V, Ulmannova T, Faresjö M: Influence of maternal hyperglycemia on cord blood mononuclear cells in response to diabetes-associated autoantigens. Scand I Immunol 2009, 183:2008-15.

24. Boussioutas A, Li H, Liu J, Waring P, Lade S, Holloway AJ, Taupin D, Gorringe K, Haviv I, Desmond PV, Bowtell DD: Distinctive patterns of gene expression in premalignant gastric mucosa and gastric cancer. Cancer Res 2003, 63:2569-77.

25. Yu CD, Xu SH, Mou HZ, Jiang ZM, Zhu CH, Liu XL: Gene expression profile differences in gastric cancer, pericancerous epithelium and normal gastric mucosa by gene chip. World J Gastroenterol 2005, 11:2390-7.

26. Galamb O, Sipos F, Molnar B, Szoke D, Spisak S, Tulassay Z: Evaluation of malignant and benign gastric biopsy specimens by mRNA expression profile and multivariate statistical methods. Cytometry B Clin Cytom 2007, 72:299-309.

27. Wu MS, Lin YS, Chang YT, Shun CT, Lin MT, Lin JT: Gene expression profiling of gastric cancer by microarray combined with laser capture microdissection. World J Gastroenterol 2005, 11:7405-12.

28. Cards Gene. [http://www.genecards.org/]

29. Hayakawa T, Yamashita K, Tanzawa K, Uchijima E, Iwata K: Growthpromoting activity of tissue inhibitor of metalloproteinases-1 (TIMP-1) for a wide range of cells. A possible new growth factor in serum. FEBS Lett 1992, 298:29-32.

30. Guedez L, Stetler-Stevenson WG, Wolff L, Wang J, Fukushima P, Mansoor A, Stetler-Stevenson M: In vitro suppression of programmed cell death of $B$ cells by tissue inhibitor of metalloproteinases-1. J Clin Invest 1998, 102:2002-10

31. Liu XW, Bernardo MM, Fridman R, Kim HR: Tissue inhibitor of metalloproteinase-1 protects human breast epithelial cells against intrinsic apoptotic cell death via the focal adhesion kinase/ phosphatidylinositol 3-kinase and MAPK signaling pathway. J Biol Chem 2003, 278:40364-72

32. Ikegawa S: Expression, regulation and function of asporin, a susceptibility gene in common bone and joint diseases. Curr Med Chem 2008, 15:724-8.

33. Kuniyasu H, Oue N, Sasahira T, Yi L, Moriwaka Y, Shimomoto T, Fujii K, Ohmori H, Yasui W: Reg IV enhances peritoneal metastasis in gastric carcinomas. Cell Prolif 2009, 42:110-21.

34. Morino M, Tsuzuki T, Ishikawa Y, Shirakami T, Yoshimura M, Kiyosuke Y, Matsunaga K, Yoshikumi C, Saijo N: Specific expression of HSP47 in human tumor cell lines in vitro. In Vivo 1997, 11:17-21.

35. Nakajima M, Shinoda I, Samejima Y, Miyauchi H, Fukuwatari Y, Hayasawa H: Lactoferrin as a suppressor of cell migration of gastrointestinal cell lines. J Cell Physiol 1997, 170:101-5.

36. Veeraraghavalu K, Pett M, Kumar RV, Nair P, Rangarajan A, Stanley MA, Krishna S: Papillomavirus-mediated neoplastic progression is associated with reciprocal changes in JAGGED1 and manic fringe expression linked to notch activation. J Virol 2004, 78:8687-700.

37. Park JY, Park KH, Bang S, Kim MH, Lee JE, Gang J, Koh SS, Song SY: CXCL5 overexpression is associated with late stage gastric cancer. J Cancer Res Clin Oncol 2007, 133(11):835-40

38. Begley LA, Kasina S, Mehra R, Adsule A, Admon AJ, Lonigro RJ, Chinnaiyan AM, Macoska JA: CXCL5 promotes prostate cancer progression. Neoplasia 2008, 10(3):244-54.

39. Wu YY, Tsai HF, Lin WC, Hsu PI, Shun CT, Wu MS, Hsu PN: Upregulation of CCL20 and recruitment of CCR6+ gastric infiltrating lymphocytes in Helicobacter pylori gastritis. Infect Immun 2007, 75(9):4357-63.

40. Gigek CO, Leal MF, Lisboa LC, Silva PN, Chen ES, Lima EM, Calcagno DQ, Assumpção PP, Burbano RR, Smith Mde A: Insulin-like growth factor binding protein-3 gene methylation and protein expression in gastric adenocarcinoma. Growth Horm IGF Res 2010, 20(3):234-8.

41. Zhang DT, Yuan J, Yang L, Guo xn, Hao ZM, Han ZY, Wu KC, Fan DM: Osteopontin expression and its relation to invasion and metastases in gastric cancer. Zhonghua Zhong Liu Za Zhi 2005, 27:167-9.

42. Mroczko B, Lukaszewicz-Zajac M, Groblewska M, Czyzewska J, Gryko M, Guzińska-Ustymowicz K, Kemona A, Kedra B, Szmitkowski M: Expression of tissue inhibitors of metalloproteinase 1 (TIMP-1) in gastric cancer tissue. Folia Histochem Cytobiol 2009, 47(3):511-6.

43. Wenqi D, Li W, Shanshan C, Bei C, Yafei Z, Feihu B, Jie L, Daiming F: EpCAM is overexpressed in gastric cancer and its downregulation suppresses proliferation of gastric cancer. J Cancer Res Clin Oncol 2009, 135(9):1277-85.

44. Koch AE, Polverini PJ, Kunkel SL, Harlow LA, DiPietro LA, Elner VM, Elner SG, Strieter RM: Interleukin-8 as a macrophage-derived mediator of angiogenesis. Science 1992, 258(5089):1798-801.

45. Viala J, Chaput C, Boneca IG, Cardona A, Girardin SE, Moran AP, Athman R, Mémet S, Huerre MR, Coyle AJ, DiStefano PS, Sansonetti PJ, Labigne A Bertin J, Philpott DJ, Ferrero RL: Nod1 responds to peptidoglycan delivered by the Helicobacter pylori cag pathogenicity island. Nat Immunol 2004, 5(11):1166-74.

46. Matsuo Y, Ochi N, Sawai H, Yasuda A, Takahashi H, Funahashi $H$ Takeyama H, Tong Z, Guha S: CXCL8/IL-8 and CXCL12/SDF-1alpha cooperatively promote invasiveness and angiogenesis in pancreatic cancer. Int J Cancer 2009, 124(4):853-61.

47. Saito S, Kitayama J, Jin ZX, Tsuno N, Kaisaki S, Seto Y, Nagawa H: Betachemokine, macrophage inflammatory protein-1 beta (MIP-1beta), is highly expressed in diffuse type human gastric cancers. J Exp Clin Cancer Res 2003, 22(3):453-9.

48. Harlin H, Kuna TV, Peterson AC, Meng Y, Gajewski TF: Tumor progression despite massive influx of activated CD8(+) T cells in a patient with malignant melanoma ascites. Cancer Immunol Immunother 2006, 55(10):1185-97.

49. Chung $\mathrm{CK}$, Antoniades HN: Expression of c-sis/platelet-derived growth factor $\mathrm{B}$, insulin-like growth factor $\mathrm{I}$, and transforming growth factor alpha messenger RNAs and their respective receptor messenger RNAs in primary human gastric carcinomas: in vivo studies with in situ hybridization and immunocytochemistry. Cancer Res 1992, 52(12):3453-9.

50. Wang CS, Wu TL, Tsao KC, Sun CF: Serum TIMP-1 in gastric cancer patients: a potential prognostic biomarker. Ann Clin Lab Sci 2006, 36(1):23-30. 
51. Mroczko B, Groblewska M, Łukaszewicz-Zajac M, Bandurski R, Kedra B, Szmitkowski M: Pre-treatment serum and plasma levels of matrix metalloproteinase 9 (MMP-9) and tissue inhibitor of matrix metalloproteinases 1 (TIMP-1) in gastric cancer patients. Clin Chem Lab Med 2009, 47(9):1133-9.

52. Frederiksen C, Lomholt AF, Davis GJ, Dowell BL, Blankenstein MA, Christensen TJ, Brunner N, Neilsen HJ: Changes in plasma TIMP1 levels after resection for primary colorectal cancer. Anticancer Res 2009, 29:75-82.

53. Parsons CJ, Bradford BU, Pan CQ, Cheung E, Schauer M, Knorr A, Krebs B, Kraft S, Zahn S, Brocks B, Feirt N, Mei B, Cho MS, Ramamoorthi R, Roldan G, $\mathrm{Ng}$ P, Lum P, Hirth-Dietrich C, Tomkinson A, Brenner DA: Antifibrotic effects of a tissue inhibitor of metalloproteinase-1 antibody on established liver fibrosis in rats. Hepatology 2004, 40(5):1106-15.

54. Kotarsky K, Sitnik KM, Stenstad H, Kotarsky H, Schmidtchen A, Koslowski M, Wehkamp J, Agace WW: A novel role for constitutively expressed epithelial derived chemokines as antibacterial peptides in the intestinal mucosa. Mucosal Immunol 2010, 3:40-48.

doi:10.1186/1475-2867-10-45

Cite this article as: Rajkumar et al.: Identification and validation of genes involved in gastric tumorigenesis. Cancer Cell International 2010 10:45.

\section{Submit your next manuscript to BioMed Central and take full advantage of:}

- Convenient online submission

- Thorough peer review

- No space constraints or color figure charges

- Immediate publication on acceptance

- Inclusion in PubMed, CAS, Scopus and Google Scholar

- Research which is freely available for redistribution

Submit your manuscript at www.biomedcentral.com/submit 